\title{
Black Rot of Kiwifruit Caused by Alternaria alternata in Korea
}

\author{
Jin-Hyeuk Kwon ${ }^{1 *}$, Mi-Geon Cheon ${ }^{1}$, Jinwoo Kim² and Yong-Bum Kwack ${ }^{3}$ \\ ${ }^{1}$ Gyeongsangnam-do Agricultural Research and Extension Services, Jinju 660-360, Korea \\ ${ }^{2}$ Department of Applied Biology, Gyeongsang National University, Jinju 660-701, Korea \\ ${ }^{3}$ Namhae Sub-Station, National Institute of Horticultural and Herbal Science of Rural Development Administration, Namhae 668- \\ 812, Korea \\ (Received on October 13, 2010; Revised on November 29, 2010; Accepted on November 29, 2010)
}

Black rot affecting fruits of kiwifruit, 'Skinny Green' (Actinidia hybrid) caused by Alternaria were found in a farmer's orchard located in Sacheon, Korea, in 2010. The disease was found exclusively on cultivar Skinny Green, which was recently developed in Korea. The typical symptoms of the disease were black spots around the remnants of the calyx of the kiwifruit, the spots gradually expanded and covered most of the calyx (Fig. 1A). The black fruit rot extended to the inside of fruits, while the outside of the lesion become hardened and mummified (Fig. 1B). Infected fruits are no longer marketable.

Alternaria often infects the blossom and young fruit through wounds and forms abundant conidia on the surface of the lesions. Since the cultivar Skinny Green is often cultivated in vinyl houses, hot and humid conditions during the summer favor disease development and spread. The infection rate of the disease in the surveyed area reached $18 \%$ in June to July, 2010. Fresh fruits with symptoms were collected from the fields and the causal pathogen was isolated from the calyx of fruits. Colonies formed on potato dextrose agar (PDA) were velvety, olivaceous, black to sooty black, with abundant sporulation and little or no sporulating aerial mycelium, and no pigment release into the medium (Fig. 1C). The optimum temperature for growth of the fungus was $25^{\circ} \mathrm{C}$. Conidia were pale brown to golden brown in color, commonly in moderately long or long chains of five to ten or more, abundantly or sparsely branched, initially long-ellipsoid, becoming ellipsoid to ovoid, obclavate to obpyriform, mostly beakless (erostrate) or with a narrowly tapered beak. They became conical, and generated secondary conidiophores of $13-35 \times 8-15 \mu \mathrm{m}$ in size. Three to five transverse septa were observed, with one to two longitudinal or oblique septa in one or two of the transverse divisions; a dark median septum was absent (Fig. 1D). Conidiophores were pale to mid-brown in color, smooth, septate, slightly swollen, and hyaline at the apex, solitary or in small fasciles, commonly branched, straight or flexuous, $80 \mu \mathrm{m}$ long $\times 4 \mu \mathrm{m}$ in wide. The detailed mycological characteristics of the species and the host range have been reported by $\mathrm{Yu}$ (2001). For pathogenicity

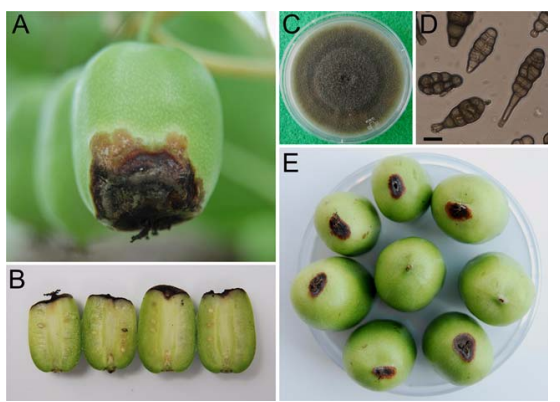

Fig. 1. Symptoms of black rot of kiwifruit and mycological characteristics of the pathogen, Alternaria alternata. A: The typical symptoms of the black rot affecting fruits in the field. B: Longitudinal section of infected fruits. C: Mycelial colony grown for 8 days on PDA. D: Conidia (bar $=10$ $\mu \mathrm{m})$. E: Symptoms induced by artificial inoculation. No symptoms were detected in fruits inoculated with water. testing, a representative isolate of the pathogen was inoculated into fresh kiwifruits through a puncture wound. The causal pathogen was re-isolated from the lesions to confirm Koch's postulation (Fig. 1E).

For further identification, we amplified and sequenced the complete internal transcribed spacer(ITS)rDNA of the isolate using the primers ITS1 and ITS4, as described by White et al. (1990). The resulting sequence of 570-bp was deposited in GenBank (Accession No.HQ257255). Phylogenetic analysis was conducted using MEGA4 software, with the neighbor-joining method and the Tajima-Nei distance model. Comparison with ITS rDNA sequences showed $100 \%$ similarity with sequences of Alternaria alternata (GQ249171) (Fig. 2). On the basis of symptoms, mycological characteristics, pathogenicity, and the ITS sequence, this fungus was identified as $A$. alternata (Fries: Fries) Keissler. Only leaf spot diseases of kiwifruit caused by Alternaria sp. have been described in Korea, and black rot on kiwifruits caused by $A$. alternata has not previously been reported (Jeong et al., 2008). The representative culture of the fungus is stored at National Academy of Agricultural Science (KACC 45440), Suwon, Korea.

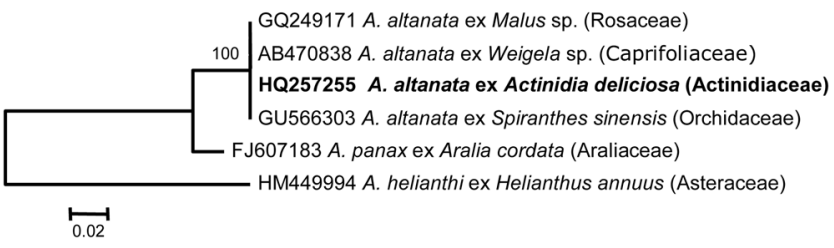

Fig. 2. Phylogenetic tree based on ITS sequences, showing closest known relatives of Alternaria alternata, including the black rot fungus infecting kiwifruit. DNA sequences from the US National Center for Biotechnology Information (NCBI) nucleotide database were aligned using ClustalW. Numbers above the branches indicate bootstrap values. Bars indicate number of nucleotide substitutions per site. The isolate infecting kiwifruit is indicated in bold.

\section{Acknowledgment}

This work was carried out with the support of "Cooperative Research Program for Agriculture Science \& Technology Development (Project No. PJ007345)" Rural Development Administration, Korea.

\section{References}

Agrios, G. N. 2005. Plant pathology. 5th ed. Academic press. London, UK. $922 \mathrm{pp}$.

Jeong, I. H., Lim, M. T., Kim, G. H., Han, T. W., Kim, H. C., Kim, M. J., Park, H. S., Shi, S. H., Hur, J. S., Shin, J. S. and Koh, Y. J. 2008. Incidences of leaf spots and blights on kiwifruit in Korea. Plant Pathol. J. 24:125-130.

White, T. J., Bruns, T., Lee, S. and Taylor, J. W. 1990. Amplification and direct sequencing of fungal ribosomal RNA genes for phylogenetics. In: PCR Protocols: A Guideto Methods and Applications, ed. by M.A. Innis, D. H. Gelfand, J. J. Sninsky, and T. J. White. pp. 315-322. Academic Press, Inc., New York, USA.

Yu, S. H. 2001. Korea species of Alternaria and Stemphylium. National Institute of Agricultural Science and Technology, Suwon, Korea. pp. 212.

*Corresponding author (Kwon825@korea.kr) 